\title{
Modelling and Control of a Fixed Calliper-Based Electronic Wedge Brake
}

\author{
Fauzi Ahmad1,2,* - Khisbullah Hudha ${ }^{3}$ - Saiful Amri Mazlan ${ }^{1}$ - Hishamuddin Jamaluddin ${ }^{4}$ - Hairi Zamzuri1 \\ Zulkiffli Abd Kadir ${ }^{1,3}$ - Vimal Rau Aparow ${ }^{3}$ \\ ${ }^{1}$ University of Technology of Malaysia, Malaysia-Japan International Institute, Malaysia \\ 2 Technical University of Malaysia, Faculty of Mechanical Engineering, Malaysia \\ ${ }^{3}$ National Defence University of Malaysia, Faculty of Engineering, Malaysia \\ ${ }^{4}$ Southern University College of Malaysia, Faculty of Engineering and Information Technology, Malaysia
}

\begin{abstract}
This paper presents a new design of an electronic fixed calliper-based wedge brake system. The movement of both sides of the brake piston is activated by a wedge block mechanism. The proposed fixed calliper-based electronic wedge brake system is a class of hydraulic-free device. The mechanism consists of two sets of wedge blocks, a ball screw drive shaft, a sliding beam and an electric motor. In this mechanism, the rotation of the shaft of the electric motor is converted into linear motion by using a ball screw drive shaft while the linear motion of the drive shaft will force the sliding beam to be displaced linearly. This will activate the wedge mechanism, which will cause the pad to be displaced tangentially to the disc brake. The movement of the pad in pressing the disc will generate clamping force and produce brake torque when the wheel rotates. In this study, the mathematical model of the system that generates the clamping force was identified. The model was based on a second order transfer function. The proposed mathematical model was then validated experimentally using a brake test rig installed with several sensors and input-output (IO) device. The performance of the brake mechanism in term of rotational input of the drive shaft and clamping force produced by the brake were observed. Accordingly, a torque tracking proportional-integral-derivative (PID) control of the system was proposed and studied through simulation and experiment. Comparisons between experimental results and model responses were made. It is found that the trend between simulation results and experimental data are similar, with an acceptable level of error.

Keywords: fixed calliper-based electronic wedge brake, clamping force system modelling and validation, torque tracking control, hardware-in-the-loop-simulation

Highlights

- This paper presents the modelling and validation of a fixed calliper-based electronic wedge brake.

- It also discusses on the effectiveness of the model in order to develop a good control strategy for the FIXEWB.

- $\quad$ Based on the developed control strategy, the effectiveness of the proposed torque tracking control of the FIXEWB was studied and presented.

- $\quad$ The control strategy developed is based on a PID controller.
\end{abstract}

\section{INTRODUCTION}

The enforcement of stringent active safety standards has led to the need for an active braking system in vehicles. An active braking system requires a fast response actuator to react effectively during critical situations. However, meeting this requirement with conventional hydraulic braking (CHB) systems is almost impossible due to its limitations, such as delayed response time up to $300 \mathrm{~ms}$, highly nonlinear two-step control, bulky size; heavy weight, and leakage in the hydraulic line [1] to [3].

Inspired by the introduction of " $x$ by wire" technology, a new braking system has been proposed as the solution to overcome the drawbacks of the CHB: electromechanical brake (EMB). However, an EMB that uses a motor linked to a gearbox requires actuation power that corresponds to the required clamping force to halt the wheel [4] and [5]. This power requirement is not sufficient where existing vehicles use only a
$12 \mathrm{~V}$ power supply. Concurrent with the extensive investigation on EMB, researchers started to search for other techniques to take advantage of the EMB in achieving higher clamping force with standard $12 \mathrm{~V}$ power supply [6]. Subsequently, an EMB-based wedge mechanism later known as electronic wedge brake (EWB) has been proposed as one of the most interesting mechanisms to be investigated.

EWB is a pure electronically controlled actuator. It typically comprises an electric motor driving a wedge mechanism to clamp and release the brake rotor [6]. As a result, it has the potential to further reduce the braking time, as well as the easier integration of advanced control features such as anti-lock braking system (ABS), vehicle stability control (VSC), electronic parking brake (EPB), etc. [6] and [7].

The investigation into EWB was first started by the German Aerospace Centre $\left(\right.$ eStop $^{\circledR}$ ) that proposed a simple and efficient mechatronic wedge brake namely eBrake ${ }^{\circledR}$ [6]. With the subsequent 
introduction of EWB, a number of EWB designs have been produced, e.g. [8] to [15], as well as studies on modelling, design, optimization and control issues of EWBs reported [16] to [20]. Despite the favourable introduction of EWB over the last decade, the brake types were similarly designed based on the floating calliper type.

The capability of EWB usage in vehicle braking system is still lacking. All the tests conducted on EWB system showed only slight improvement; they were done only through modelling and validation. In contrast, successful implementations of EWB usage in vehicle braking system were reported by [7] and [20]. However, the experimental results obtained were not as expected theoretically [20]. According to [20], the disparities between the simulation and the experimental data were caused by the simplification and idealization during modelling of the system.

Generally, in the modelling of a dynamic system, two techniques can be used; the physical parametric estimation method (PPEM) and the system identification method (SIM). PPEM refers to the models in which the characteristic of the systems can be represented as linear and non-linear elements with defined parameters. However, SIM is entirely based on the performance of specific systems commonly depicted from a series of experiment input and output data. In this condition, it is best to say that, the modelling technique used by [20] is based on PPEM, which probably causes the disparities. The technique has also been used by [7], [8], [12], [19] and [21] resulting in more than 10 percent disparity between simulation and experimental results [12]. This is due to the PPEM technique needing several assumptions that might degrade the adequacy of the model. In order to overcome this problem, the SIM technique is a good and may be a better way to be used. This is because of the ability of the technique that can produce an adequate mock-up of the proposed system with less than $5 \%$ error [16].

The global demand in the automotive vehicle sector today is for a vehicle that can provide a high dynamic response; therefore, a high capacity braking system is needed. A fixed calliper-based electronic wedge brake (FIXEWB) is thus proposed in this study. Basically, the proposed design of FIXEWB is a replacement to the fixed calliper-based CHB. Meanwhile, the SIM technique was then proposed to develop a mathematical equation of the FIXEWB. Based on the model, a torque tracking control of the system was then developed by using PID controller and validated experimentally using a hardware-in-the-loopsimulation technique.

\section{THE FIXEWB}

As the effective braking force generated is dependent on the angle of the wedge, the determination of the optimum wedge angle needed is essential. Since the optimum wedge angle is interdependent with the friction coefficient of the brake pad, the selection of brake pad should be made first. These two factors are very important in the initial decision process in order to produce a higher braking force and also to avoid the probability of the wedge sticking. Therefore, in this study, the brake pad used in a Malaysian national car was selected for the design consideration of the EWB and particularly the wedge angle. By referring to the SAE standard on brake pad [22] to [25], the E code shown on the pad indicates that the coefficient of friction of the pad lies between 0.25 to 0.35 , as listed in Table A1 in the Appendix.

To select an appropriate wedge angle, the work done by [10] is referenced. Fig. 1 shows the free body diagram of one side of the FIXEWB mechanism. Note that $\alpha_{w}$ is the angle of the wedges, $F_{r}$ is the wedge friction force that occurs between the inner and outer wedges, $F_{m}$ is the motor force to the wedge and $\mu$ is the pad coefficient of friction. Assuming that the motor force is divided equally to both sides of the wedges and the forces acting on the left wedge is the same as on the right wedge, the relationship between the wedge pushing forces, friction forces, clamping forces, and braking forces to the disc for both sides of the wedges is given by:

Summation of force in $y$ direction:

$$
\begin{gathered}
\sum F_{y}=0, \\
F_{m}+F_{r} \sin \alpha_{w}+F_{b}=0,
\end{gathered}
$$

therefore,

$$
F_{r} \sin \alpha_{w}=-\left(F_{b}+F_{m}\right) .
$$

Summation of force in $x$ direction

$$
\begin{gathered}
\sum F_{x}=0, \\
-F_{r} \cos \alpha_{w}-F_{n}=0,
\end{gathered}
$$

therefore,

$$
F_{r} \cos \alpha_{w}=-F_{n} .
$$

By dividing Eq. (3) with Eq. (6), the summation of force at the wedge can be defined as follows:

$$
\tan \alpha_{w}=\frac{F_{b+F_{m}}}{F_{n}} .
$$


Noted that $F_{n}=F_{c}$ therefore $F_{b}=\mu F_{c}$. Rearrange Eq. (7) to be:

$$
F_{c} \tan \alpha_{w}=F_{m}+\mu F_{c} .
$$

Hence

$$
F_{c}=\frac{F_{m}}{\tan \alpha_{w}-\mu} .
$$

a)

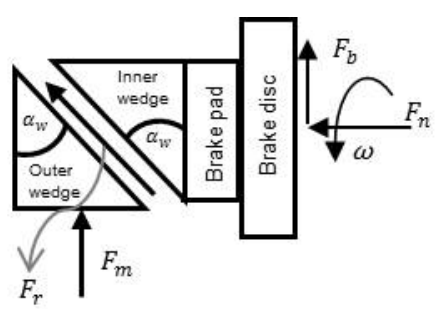

b)

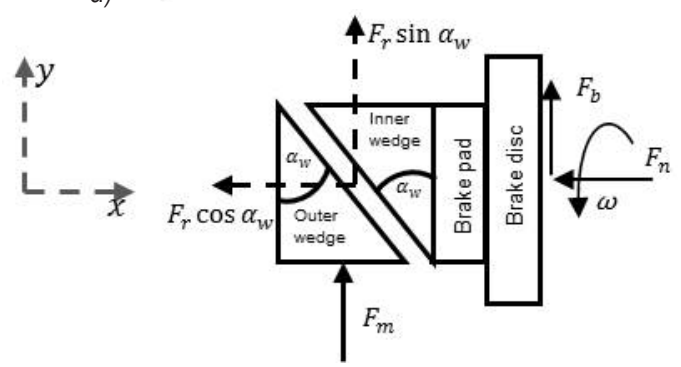

Fig. 1. Free body diagram of FIXEWB; a) one side of FIXEWB, b) friction force distribution

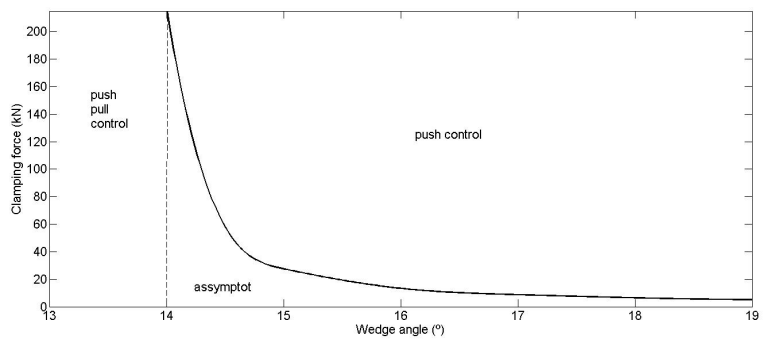

Fig. 2. Clamping forces vs. wedge angle

As shown in Fig. 2, the relationship between clamping force and the wedge angle can be described by employing Eq. (3) by assuming $F_{m}$ is $500 \mathrm{~N}$ and $\mu$ is 0.25 (according to the selected brake pad). It can be seen that the critical angle of the wedge is about $14.03^{\circ}$ which is equal to $\tan \alpha_{w}=\mu$. In this condition, the clamping force is self-generated resulting from the friction between the wedges to the disc brakes. However, if the wedge angle is less than the critical angle, it will cause the actuator to work harder to push the wedge. When the pad and disc are in contact, the braking force created is greater than the force initiated from the actuator and causes greater pulling force that is needed to release the wedge. Therefore, in this study, the optimum wedge angle was chosen to be $15^{\circ}$ to ensure the larger clamping forces can be produced, which are easy to control and to prevent the wedge from being jammed.

The effectiveness of the selected wedge angle can be examined by introducing the required motor force by varying the coefficient of friction. Fig. 3 was obtained by assuming the clamping force of 46 $\mathrm{kN}$ and varying the coefficient of friction from 0.25 to 0.35 . From the figure, it can be seen that $1 \mathrm{kN}$ motor force is required to create the desired clamping force at the initial condition. While at the coefficient of friction of 0.267 , self-reinforcement will exist; thus, no motor force is needed. Other than that, as the coefficient of friction increases, the motor force becomes negative. The shifting from the positive to the negative force indicates that when the mechanism is working to sustain the required clamping force by varying the friction coefficient, the wedge needs to be repositioned hence retraction control is needed. Based on the optimised wedge angle, the CAD design of the FIXEWB is shown in Fig.4.

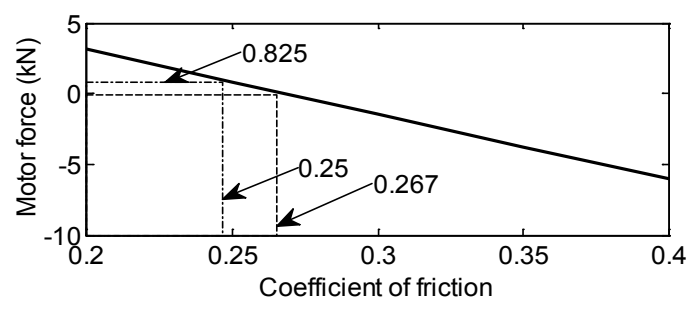

Fig. 3. Motor force vs. coefficient of friction

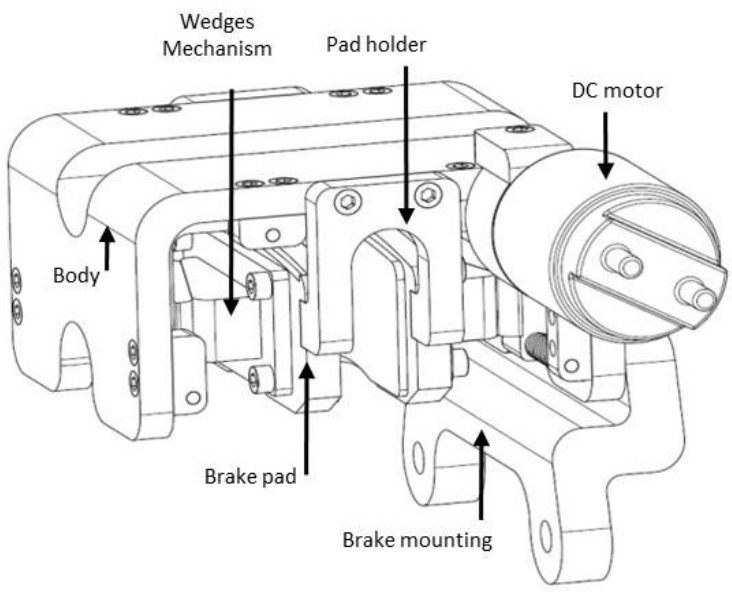

Fig. 4. FIXEWB concept design

\subsection{Hardware of FIXEWB}

The hardware of FIXEWB is shown in Fig. 5. The FIXEWB is driven by a DC motor that is directly 
connected with a slider beam through a drive shaft. The slider beam, which enables forward and back movements, will initiate the inner wedges to move tangentially to the slider beam movement hence clamping the brake disc. The on-off condition of the brake is shown in Fig. 6 .

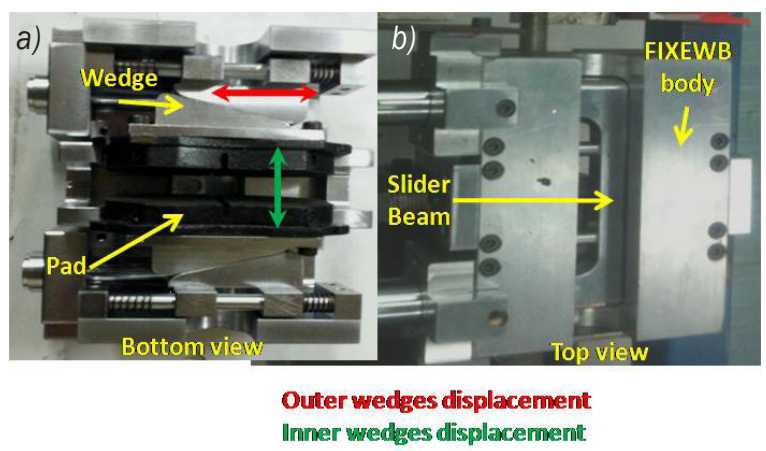

Fig. 5. FIXEWB hardware, a) bottom view and b) top view

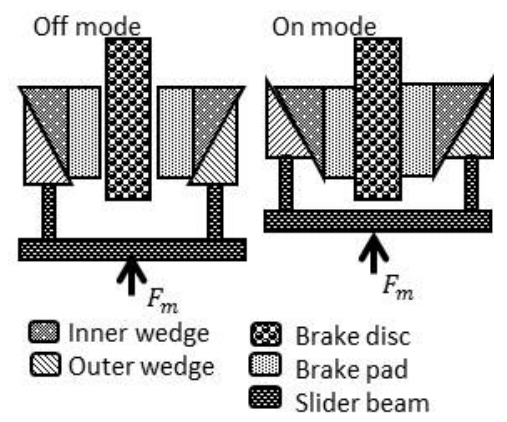

Fig. 6. On-off mode FIXEWB

\subsection{FIXEWB Test Rig and Experimental Setup}

As shown in Fig.7, the FIXEWB test rig consists of a FIXEWB actuator equipped with a data acquisition system, a force sensor and a potentiometer. The potentiometer was attached to the drive shaft to measure the rotational input to the calliper. The force sensor attached to the brake pad is used to measure the clamping force produced by the brake system. A National Instrument NI PCI 6221 card along with SCB68 Quick reference label M-Series device were used as the data logger, and an electronic control unit (ECU) was used as the embedded system to control the FIXEWB. The ECU consists of three main circuits: a microcontroller unit (MCU ATMEGA 32, an optocoupler, and H-Bridge driver circuits as the current buffer to drive the system. The hardware of the ECU is shown in Fig. A1 in the Appendix.

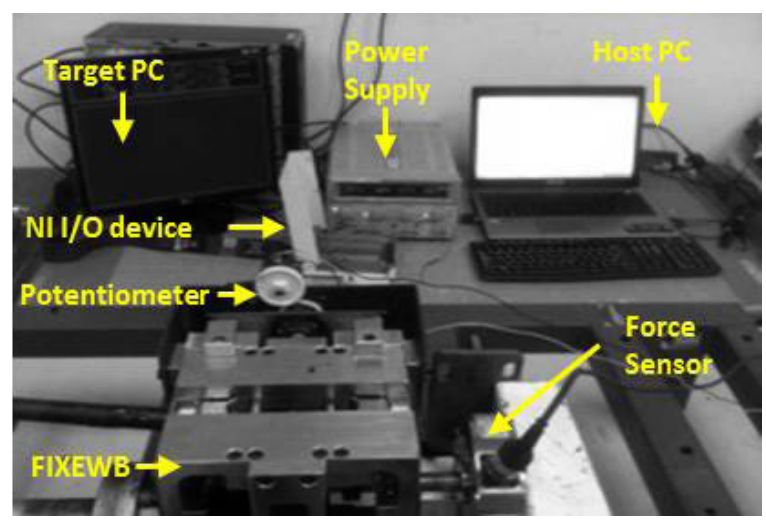

Fig. 7. FIXEWB test bench

Before experimental work was performed, the initial gap between the brake pad and the force sensor was set to approximately $0.5 \mathrm{~mm}$ by using a filler gauge. From this experiment, the responses measured were angle displacement and clamping force of the system as shown in Fig. 8 .
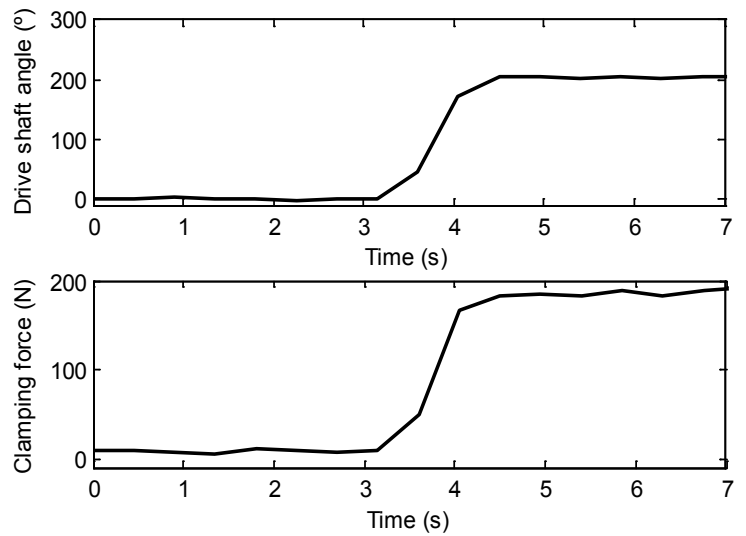

Fig. 8. Training data obtained

\section{CLAMPING FORCE MODELS AND BRAKE TORQUE CALCULATION OF FIXEWB}

Based on the training data obtained from the experiment shown in Fig. 8, a transfer function (TF) was developed to represent the relationship between the input and output of the system. In this system, the $\mathrm{TF}$ is expressed as the ratio of the Laplace transform of the clamping force and the drive shaft angle and corresponds to the Laplace transform of the impulse response $G(s)$. The transfer function of the system identified using the system identification method is:

$$
G(s)=\frac{1.508}{s^{2}+0.571 s+0.7492} .
$$


By referring to Fig. 9, the braking torque at the contact interface can be predicted as:

$$
T_{b}=R_{e f f} F_{c},
$$

where, $T_{b}$ is the brake torque, $R_{\text {eff }}$ is the effective pad radius and $F_{c}$ is the clamping force. However, the friction force generated at the contact interface, $F_{b}$ is dependent on normal force $\left(F_{n}\right)$ and friction coefficient $(\mu)$, given by:

$$
F_{b}=\mu F_{n} .
$$

The magnitude of the normal force is the same as the clamping force $\left(F_{c}\right)$ applied to the top of the pad, as shown in Fig. 9. Since there is a pair of brake pads in the brake system, the total brake torque is:

$$
T_{b}=2 \mu F_{c} .
$$

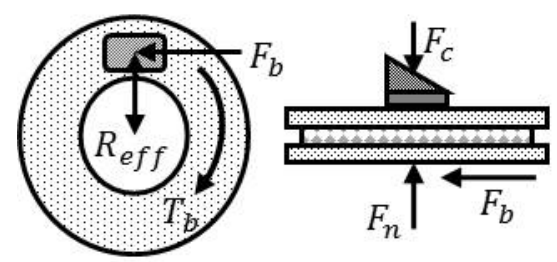

Fig. 9. Brake torque model in contact interface side and top view

\subsection{Motor Model}

In this FIXEWB system, a permanent magnet direct current motor (DC motor) was used to drive the FIXEWB. A DC motor is used because of several advantages, such as higher reliability since there are no brushes that may be susceptible to mechanical failure, reduced heat dissipation from the rotor, higher torque-to-inertia ratio, and a significant reduction in friction. The mathematical equations of the DC motor can be found in [9].

\subsection{Validation of FIXEWB Model}

The validation results of the proposed mathematical model for the FIXEWB are shown in Figs. 10 to 12. Several validation tests have been employed by varying the magnitude of the drive shaft angle i.e. step input, multiple step input and sine wave. The parameters of the model are defined as follows: $\mu=0.25$ and $R_{\text {eff }}=150 \mathrm{~mm}$. As shown in Fig. 10, the step input function has been used as the input rotation to the calliper, the output of the system is the clamping force resulting from the displacement of the wedges and the brake pad. It is noted that for $200^{\circ}$ rotational input to the drive shaft, an approximately about 400 $\mathrm{N}$ clamping force and a $30 \mathrm{Nm}$ braking torque are generated.
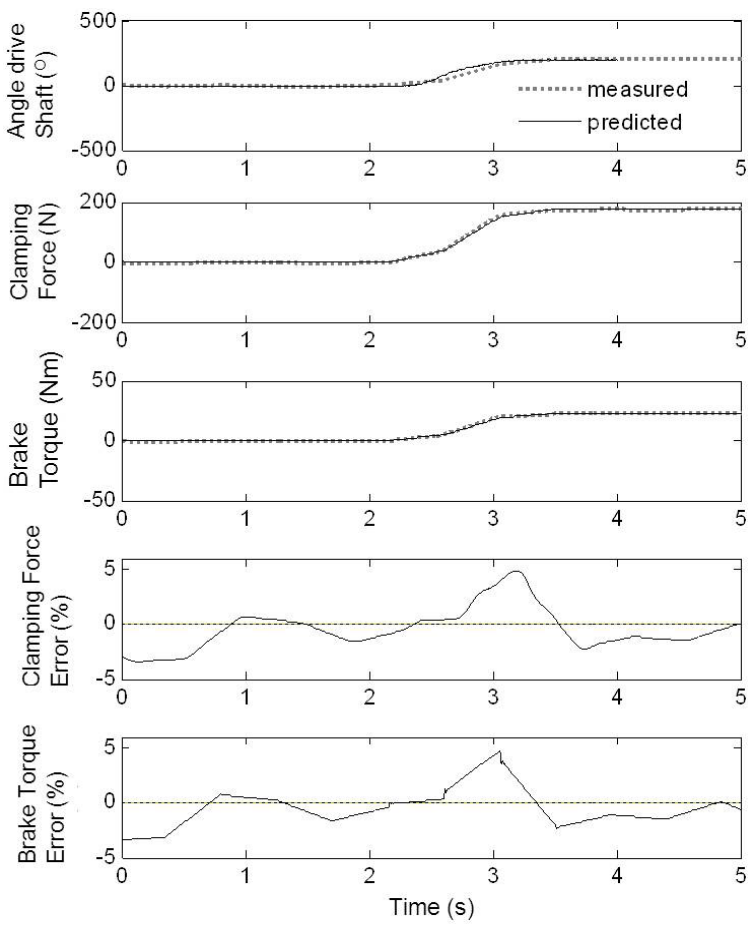

Fig. 10. Validation using step input

To validate the model further, another observation has also been made by using multiple steps input and sine input. The multiple steps and sine input tests were used to assess the effectiveness of the developed equation in order to present a continuous input to the system. As shown in Figs. 11 and 12, it can be seen that the trends between simulation results and experimental data are almost similar with acceptable errors in terms of the drive shaft displacement, clamping forces, and the brake torque produced. It was noted that the deviations between the simulation and the experimental data are almost less than $5 \%$. Some deviation in the experimental results is possibly caused by backlash at the connection between the DC motor and the drive shaft and the frictions between the mechanical moving parts that produced delay behaviour.

Overall, it is noted that the trends between simulation results and the experimental data are in good agreement with acceptable error. Conversely the error can be significantly reduced by fine tuning the modelling parameters. However, excessive fine tuning can be avoided since in the control-oriented model, the most important characteristic is the trends of the model response. As long as the trend of the model 
is closely similar with the measured response with acceptable deviation in magnitude, it can be said that the model is adequate.
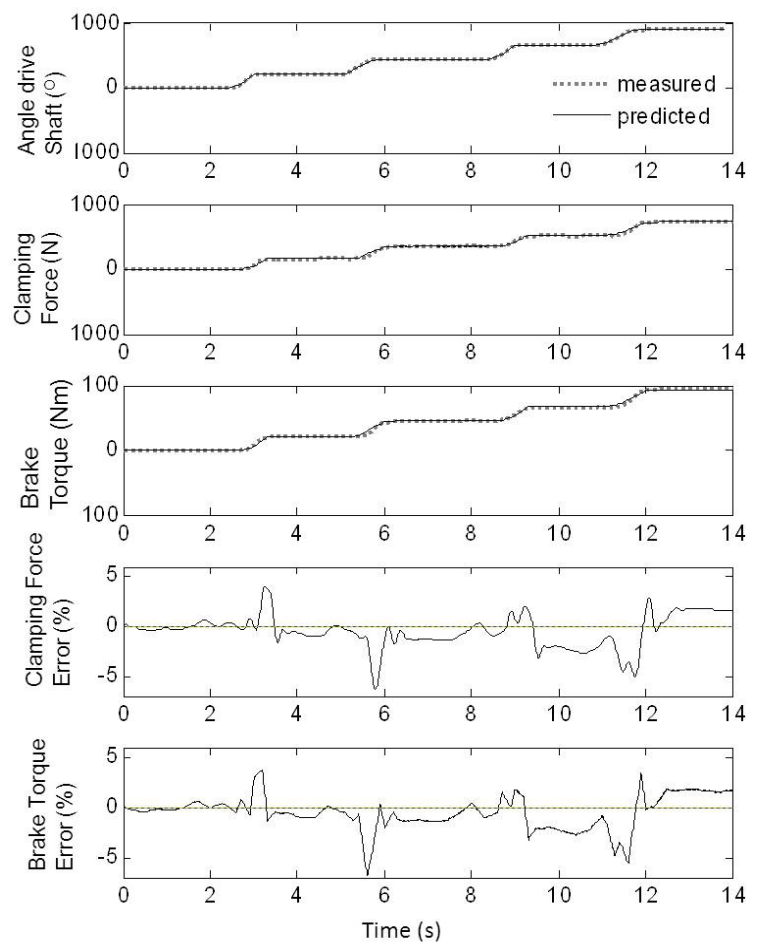

Fig. 11. Validation using multiple steps input
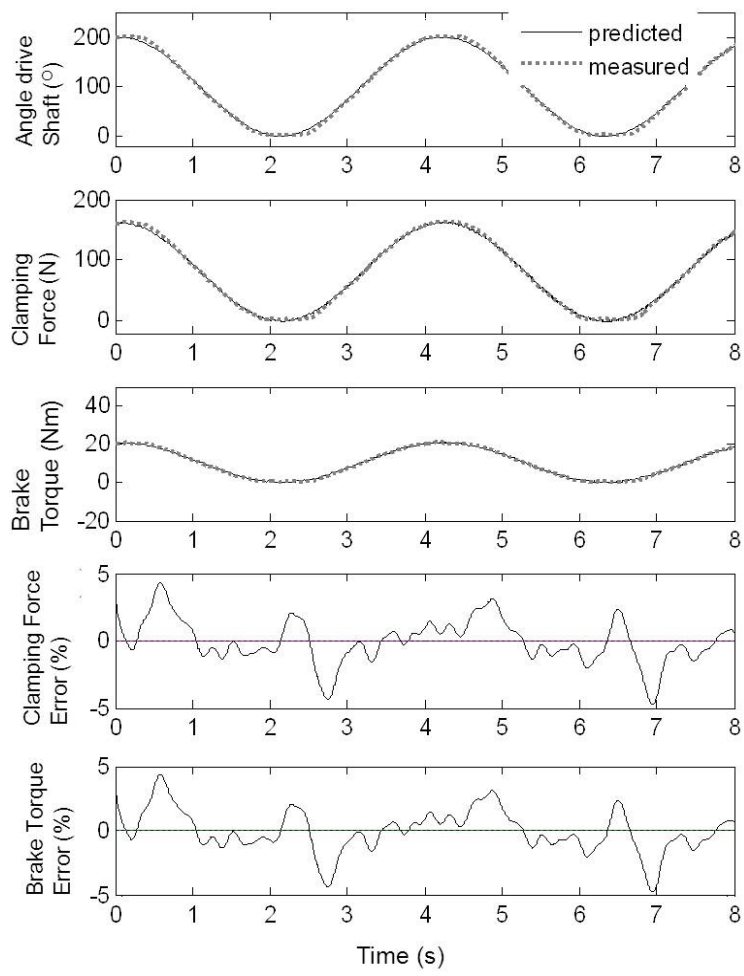

Fig. 12. Validation using sine input

\section{FIXEWB CONTROLLER}

The basic control structure of the proposed FIXEWB control is shown in Fig. 13. In this control structure, three control loops are employed, which are torque, speed and position control loops. For the torque controller, a proportional integral derivative (PID) based feedback controller was used. As the braking ability is influenced by a driving style that sometimes needs fast and slow braking responses, the brake actuator needs to work in a wide range of speed. Therefore, another feedback-based P controller, which acts as a speed controller, was used for maintaining the braking torque by allowing the motor to rotate at high speed regardless of the braking torque demand. The other loop is the position control-based PID controller used to maintain the gap distance between the pad and the disc brake. The controller parameters were tuned using Ziegler-Nichols method and the tuned controller parameters are shown in Table 1. The performance observed is brake torque tracking performance. Several test signals were used as the torque demand, which are the step, sine wave, square wave and saw tooth functions with magnitudes of $400 \mathrm{Nm}, 800 \mathrm{Nm}$ and $1200 \mathrm{Nm}$.

Table 1. Controller parameters

\begin{tabular}{lccc}
\hline Controller & $\mathrm{P}$ & $\mathrm{I}$ & $\mathrm{D}$ \\
\hline Brake torque & 0.5411 & 3.809 & 0.02623 \\
\hline Position & 30 & 2 & 1 \\
\hline Speed & 0.01 & - & - \\
\hline
\end{tabular}

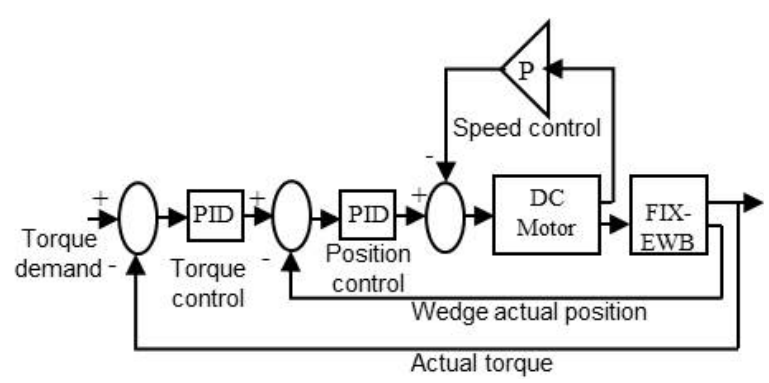

Fig. 13. FIXEWB controller structure

\subsection{Performance Evaluation of Torque Tracking Controller of FIXEWB}

Fig. 14 shows the performance evaluation of the torque tracking controller using a step input function. It can be seen that there is good agreement between the simulation results with the experimental data. For 400 Nm, 800 Nm, and 1200 Nm peak torque, Fig. 14 
shows the ability of the controller structure in tracking the desired trajectory is very promising. However, there are some deviations between the responses for $1200 \mathrm{Nm}$ (Fig. 14c), where the experimental response is slightly slower in comparison to the simulation with the difference about $1.25 \mathrm{~s}$. Meanwhile, the percentage overshoot for $400 \mathrm{Nm}, 800 \mathrm{Nm}$, and $1200 \mathrm{Nm}$ peak torque in simulation are $5 \%$ while in the experimental responses, the percentage overshoot for both $400 \mathrm{Nm}$, $800 \mathrm{Nm}$, and $1200 \mathrm{Nm}$ are $1.38 \%, 7.5 \%$, and $6.3 \%$, respectively. For the torque of $800 \mathrm{Nm}$, the settling time of the simulation and the experimental results are $4.8 \mathrm{~s}$ and $5.3 \mathrm{~s}$, respectively, while for $1200 \mathrm{Nm}$ the simulation and experimental results are $4.8 \mathrm{~s}$ and $6.06 \mathrm{~s}$, respectively.

The torque tracking for sinusoid function with various peak torques shows good tracking performances between simulation and experimental results. This can be seen in Fig. 15, where there is good agreement between the simulation results and the experimental data, even though nonlinearities exist in the experimental responses.

The performance evaluations of tracking torque for sawtooth function with various peak torques are shown in Fig. 16. It can be seen that for this input function the torque tracking system is quite good, although it is unable to closely follow the desired torque, especially at the peak. However, it can be seen from the figure that the performance is poor when the actuator provides negative torque; meanwhile, when providing positive torque, the performance of torque tracking control is excellent. Aside from that, it is observed that there are jerk phenomena in between the maximum and minimum peak torque. This jerking is due to the extra effort needed by the actuator to follow the desired trajectories while at the same time the motor speed is limited.

For the square input function shown in Fig. 17, the system shows the tendency to follow the desired torque with similar trends for both simulations and experiments. However, the effort by the controller to produce a fast time response has led the system to produce high percentage overshoots and slower settling times. The percentage overshoot for simulation with $400 \mathrm{Nm}, 800 \mathrm{Nm}$ and $1200 \mathrm{Nm}$ are $12.37 \%, 22.5 \%$ and $23.34 \%$ respectively, while for experiments are $12.33 \%, 23.1 \%$, and $23.37 \%$, respectively. The average settling time for simulations is about $4.58 \mathrm{~s}$ while for experiment results it is around $4.63 \mathrm{~s}$. Otherwise, the average rise times at $100 \%$ target value between the desired torques with simulation and experimental data are about $0.36 \mathrm{~s}$ and $0.57 \mathrm{~s}$, respectively.

The deviations between simulation and the experimental data may be due to the load disturbance from the moving part in the hardware that lowers the speed of the system. For the simulation, the masses of the moving parts in a mechanical system, such as a pad and slider beam, were ignored but not in the actual model. Furthermore, the finishing of the hardware and the limitation of DC motor may also contribute to the slow response of the system. However, the study
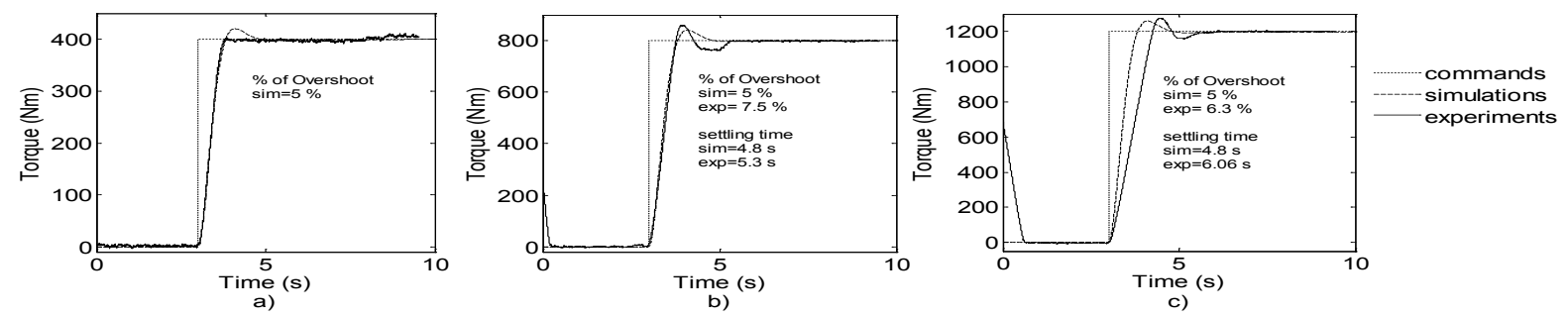

Fig. 14. Step functions responses, a) $400 \mathrm{Nm}$, b) $800 \mathrm{Nm}$ and c) $1200 \mathrm{Nm}$
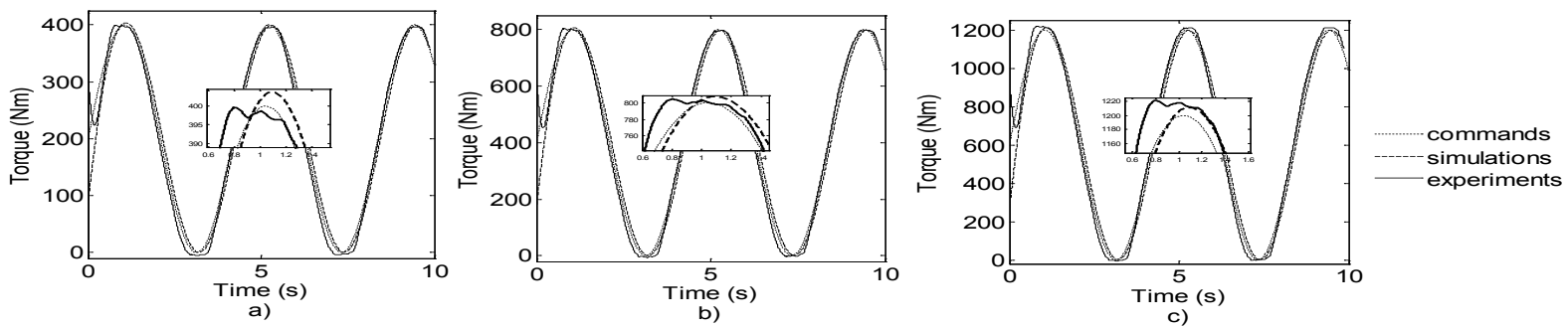

Fig. 15. Sine functions responses, a) $400 \mathrm{Nm}$, b) $800 \mathrm{Nm}$ and c) $1200 \mathrm{Nm}$ 

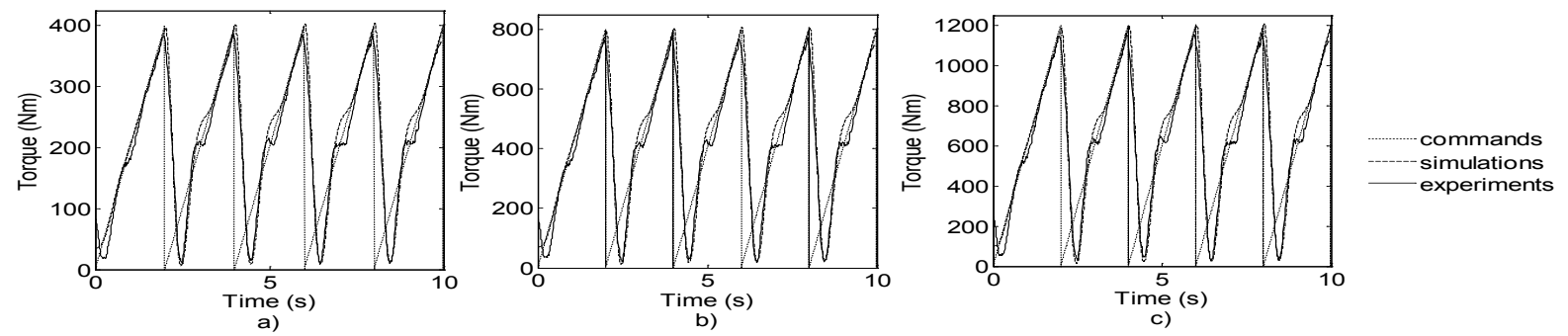

Fig. 16. Saw tooth functions responses, a) $400 \mathrm{Nm}$, b) $800 \mathrm{Nm}$ and c) $1200 \mathrm{Nm}$
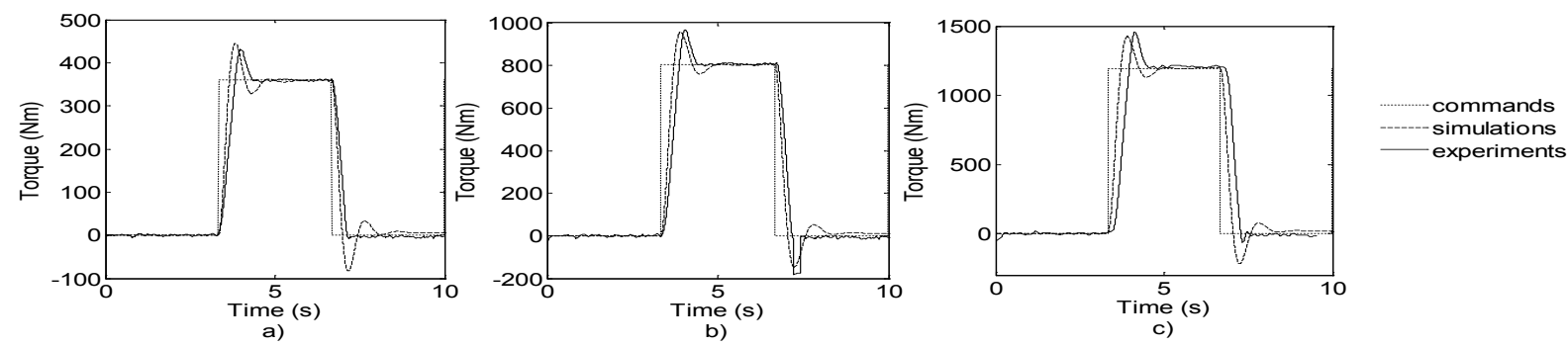

Fig. 17. Square functions responses, a) $400 \mathrm{Nm}$, b) $800 \mathrm{Nm}$ and c) $1200 \mathrm{Nm}$

has shown the proposed transfer function is adequate to be used as a model of FIXEWB for simulation. The combination of mathematical modelling with an appropriate control strategy produced overall good responses of the system with good performance and acceptable stability. It is shown for torque tracking of step, sine wave, and square input functions; the ability of the simulation system to track the desired trajectory is promising and agreeable with the experimental result even though there is a slight deviation for saw tooth input function. It also indicates that the proposed system together with the control strategy performs well in a real system and shows the capability of the system applied to a real system.

\section{CONCLUSION}

In this study, a fixed calliper-based electronic wedge brake has been designed and fabricated. The FIXEWB system consisted of two sets of wedge mechanism, drive shaft, slider beam and an electric motor as the actuator. The transfer function model of the brake mechanism was identified to represent the dynamic behaviour of the proposed FIXEWB. Then, by combining the FIXEWB model with the brake torque model in contact interface, the brake torque produced by the FIXEWB system can also be estimated. The predicted responses of both clamping force output from the FIXEWB model and brake torque were compared with the measured responses of both clamping force and brake torque obtained using the FIXEWB test rig. The results showed that the responses of the model were in good agreement with the response of a real FIXEWB system. By using the validated FIXEWB model, a brake torque controlbased PID controller was developed. The controller strategy consisted of three control loops (actuator position control loop, actuator speed control loop, and brake torque control loop) was designed. To verify the effectiveness of the controller strategy, a torque tracking control of the FIXEWB was performed in both simulation and experimental studies. Several tests were conducted such as brake torque demand of $400 \mathrm{Nm}, 800 \mathrm{Nm}$ and $1200 \mathrm{Nm}$ for step, sine, sawtooth and square input functions, respectively. The results demonstrated that the proposed FIXEWB model along with a suitable control structure is able to produce good performance and closely follow the desired torque for step, sine, sawtooth, and square functions. The simulation behaviour was found to be agreeable with the experiment's data. This is due to the ability of the developed mathematical model to describe the behaviour of the FIXEWB adequately and the effectiveness of the controller strategy. Therefore, it is demonstrated that the torque control scheme is suitable to be applied in the inner loop part of the vehicle brake system as well as in the active braking particularly in ABS systems. 


\section{ACKNOWLEDGEMENTS}

This work is part of a research project entitled "Robust stabilization of armoured vehicle firing dynamic using active front wheel steering system", funded by LRGS grant (No. LRGS/B-U/2013/UPNM/DEFENSE \& SECURITY - P1).

\section{REFERENCES}

[1] Kim, J., Jo, C., Kwon, Y., Cheon, J.S., Park, S.J., Jeon, G.B., Shim, J. (2014). Electro-mechanical brake for front wheel with back-up braking. SAE International Journal of Passenger Cars - Mechanical System, vol. 7, no. 4, p. 1369-1373, DOI:10.4271/2014-01-2538.

[2] Haggag, S., Abidou, D. (2013). An approach to vehicle brakeby-wire optimal control tracking strategy. SAE International Journal of Passenger Cars - Mechanical System, vol. 6, no. 1, p. 154-162, Dol:10.4271/2013-01-0686.

[3] Karakoc, K. (2005). Design of a Magnethorheological Brake System Based on Magnetic Circuit Optimization. MSc Thesis. University of Victoria, Victoria, available at: https://dspace. library. uvic. ca//handle/1828/197, accessed on: 2016-2201.

[4] Schwarz, R., Isermann, R., Böhm, J., Nell, J., Rieth, P. (1998). Modelling and control of an electromechanical disk brake. SAE Technical Paper, paper no: 980600, D0l:10.4271/980600.

[5] Day, A. (2014). Electronic braking systems. Braking of Road Vehicles. Chapt. 11, p. 385-428, Elsevier, London, DOI:10.1016/B978-0-12-397314-6.00011-5.

[6] Hartmann, H., Schautt, M., Pascucci, A. Gombert, B. (2002). eBrake $^{\circledR}$ - The mechatronic wedge brake. SAE Technical Paper, paper no. 2002-01-2582, D0l:10.4271/2002-01-2582.

[7] Roberts, R., Schautt, M., Hartmann, H., Gombert, B. (2003). Modelling and validation of the mechatronic wedge brake. SAE Technical Paper, paper no. 2003-01-333, D0I:10.4271/200301-3331.

[8] Ho, L., Roberts, R., Hartmann, H., Gombert, B. (2006).The electronic wedge brake-EWB. SAE Technical Paper, paper no. 2006-01-3196, DOI:10.4271/2006-01-3196.

[9] Semsey, Á., Roberts, R. (2006). Simulation in the development of the electronic wedge brake. SAE Technical Paper, paper no. 2006-01-3196, D0I:10.4271/2006-01-0298.

[10] Emam, M.A.A., Emam, A.S., El-Demerdash, S.M., Shaban S.M., Mahmoud, M.A. (2012). Performance of automotive self-reinforcement brake system. Journal of Mechanical Engineering, vol. 1, no. 1, p. 4-10.

[11] Shin, D. H., An, J. N. (2012). Study of stiffness design of calliper for reducing the weight of an electronic wedge brake. Applied Mechanics and Materials, vol. 138-139, p. 159-162, DOl:10.4028/ www.scientific.net/AMM.138-139.159.

[12] Han, K., Kim, M., Huh, K. (2012). modelling and control of an electronic wedge brake. Proceeding of the Institution of Mechanical Engineers, Part C: Journal of Mechanical Engineering Science, vol. 226, no. 10, p. 2440-2455, DOl:10.1177/ 0954406211435584.
[13] Abd. Rahman, M. L. H., Hudha, K., Ahmad, F., Jamaluddin, H. (2013). Design and clamping force modelling of electronic wedge brake system for automotive application. International Journal of Vehicle Modelling and Testing, vol.8, no. 2, p. 145156, DOI:10.1504/IJVSMT.2013.054478.

[14] Kim, J., Kim, M., Kim, J., Noh, K. (2009). Developing of electronic wedge brake with cross wedge. SAE Technical Paper, paper no. 2009-01-0856, D0l:10.4271/2009-01-0856.

[15] Kim, J. (2011). Single Motor Electro Wedge Brake System Using Solenoid Mechanism for Implementing Additional Functions. United States Patent \& Trademark office, Washington, D.C., US 20080314695.

[16] Aparow, V. R., Hudha, K., Ahmad, F., Jamaluddin, H. (2015). Modeling and validation of electronic wedge brake mechanism for vehicle safety system. Jurnal Teknologi (Science \& Engineering), vol. 75, no. 1, p. 183-191, D0l:10.11113/ jt.v75.2778.

[17] Fox, J., Roberts, R. Baier-Welt, C., Ho, L. M., Lacraru, L. Gombert, B. (2007). Modelling and control of a single motor electronic wedge brake. SAE Technical Paper, paper no. 200701-0866, D0I:10.4271/2007-01-0866.

[18] Han, K., Huh, K., Hwang, W., Kim, M., Kim, D. (2012). EWB control based on the estimated clamping force. SAE Technical Paper, paper no. 2012-01-1797, D0I:10.4271/2012-01-1797.

[19] Roberts, R., Gombert, B., Hartmann, H., Lange, D., Schautt, M. (2004). Testing the mechatronic wedge brake. SAE Technical Paper, paper no. 2004-01-2766, D0I:10.4271/2004-01-2766.

[20] Cheon, J. (2010). Brake by wire system configuration and functions using front EWB (electric wedge brake) and rear EMB (electro-mechanical brake) actuators. SAE Technical Paper, paper no. 2010-01-1708, D0I:10.4271/2010-01-1708.

[21] Ghajari A., Kazemi, R. (2012). A New approach to the electronic wedge brake. SAE Technical Paper, paper no. 201201-1801, D0I:10.4271/2012-01-1801.

[22] SAE Standard J866 (2012). Friction Coefficient Identification and Environmental Marking System for Brake Lining. SAE International Vehicle Recommended Practice.

[23] Sayim, I., Zhang, D. (2016). Optimization of the Brake Factor for an S-Cam Foundation Brake using RSM. Strojniški vestnik Journal of Mechanical Engineering, vol. 62, no. 9, p. 503-510, D0I:10.5545/sv-jme.2016.3459.

[24] Karabay, S., Baynal, K., Igdeli, C. (2013). Detecting Groan Sources in Drum Brakes of Commercial Vehicles by TVAFMEA: A Case Study. Strojniški vestnik - Journal of Mechanical Engineering, vol. 59, no. 6, p. 375-386, D0l:10.5545/svjme.2012.809.

[25] Grkić, A., Mikluc, D., Muždeka, S., Arsenić, Ž., Duboka, C. (2015). A model for the estimation of brake interface temperature. Strojniški vestnik - Journal of Mechanical Engineering, vol. 61, no. 6, p. 392-398, D0l:10.5545/svjme.2014. 2364. 
7 APPENDIX

Table A1. Friction coeffcient code SAE Standard, [22]

\begin{tabular}{cc}
\hline Code letter & Coefficient of friction \\
\hline C & Not over 0.15 \\
\hline$D$ & Over 0.15 but not over 0.25 \\
\hline$E$ & Over 0.25 but not over 0.35 \\
\hline$F$ & Over 0.35 but not over 0.45 \\
\hline$G$ & Over 0.45 but not over 0.55 \\
\hline$H$ & Over 0.55 \\
\hline$Z$ & Unclassified \\
\hline
\end{tabular}

Microcontroller unit

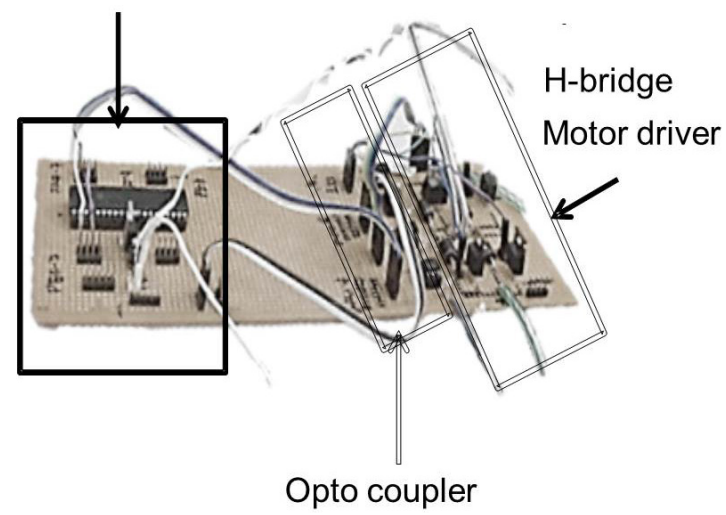

Fig. A1. Electronic control unit 